\title{
IMAGENS DE SI: O AUTORRETRATO COMO PRÁTICA DE CONSTRUÇÃO DA IDENTIDADE
}

\author{
DOI: http://dx.doi.org/10.5965/198431781112015051
}

\author{
Roselene Maria Rauen ${ }^{1}$ \\ Daniel Bruno Momoli ${ }^{2}$
}

\section{RESUMO}

Esta pesquisa tem como tema "Imagens de si: o autorretrato como prática de construção da identidade". Apresenta como campo problemático os caminhos possíveis para uma discussão: Pensar a nossa identidade vai além de simplesmente responder a pergunta: Quem sou eu? Vai além de um nome, idade, sexo, profissão, grau de escolaridade? Ao desenvolvermos atividades que estimulem o processo de exploração de si proporcionaremos que o individuo identifique e demonstre suas próprias características, seus anseios e percepções, buscando explicitar de forma concreta seu "eu"? O autorretrato pode contribuir no processo de construção da identidade? O objetivo geral do trabalho é desenvolver um estudo sobre o autorretrato para a prática de construção da identidade desenvolvendo a observação e sensibilidade do olhar em relação a si no ensino de artes visuais. No capítulo dois intitulado "Conceituação e contexto" apresentamos algumas definições importantes sobre o retrato e o autorretrato na história da arte, tais como, conceitos e contexto histórico, além de discorrermos sobre o autorretrato como prática de construção da identidade. No capítulo três "Autorretratos em estudo: autorrepresentação, dualidade, multiplicidade e ilusão" analisamos a produção de autorretratos do artista holandês Rembrandt a fim de buscar compreender esse gênero e explorá-lo para verificar se essa prática pode auxiliar na busca da construção da identidade. No capítulo quatro intitulado "A prática do autorretrato: um momento de reflexão e construção da identidade" apresentamos alguns autorretratos feitos nas oficinas e breves relatos dos participantes. Consideramos o autorretrato como a forma expressiva da imagem, representação, apresentação, expressão e conhecimento de si para si mesmo. As categorias de análise foram: o fazer (processo de produção poética e de constituição/afirmação da identidade do sujeito), o exprimir (sentido, significação, apresentação e representação), os elementos visuais e os relatos pessoais do sujeito (conhecimento de si). Tomamos aqui a arte como um espaço social construtor de subjetividades. O indivíduo ao se autorretratar organizou seus pensamentos, seus sentimentos, com o objetivo de dar significado a sua imagem. Trata-se de um processo complexo que envolve pensar, expressar, interpretar, criar e transmitir.

Palavras-Chave: Autorretrato. Identidade. Rembrandt.

\author{
ABSTRACT \\ 1 Uniarp - Universidade Alto Vale do Rio do Peixe \\ 2 Uniarp - Universidade Alto Vale do Rio do Peixe
}




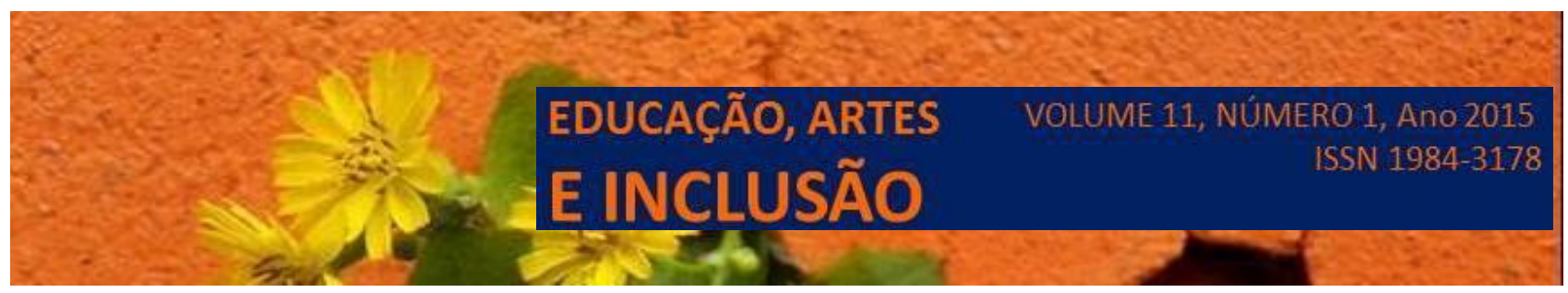

This research has the theme "images of themselves: the self-portrait as a practice of identity construction." It presented as problematic field possible paths for a discussion: Think our identity goes beyond simply answering the question: Who am I? It goes beyond a name, age, sex, occupation, education level? By developing activities that stimulate the process of exploration itself will provide the individual identify and demonstrate their own characteristics, their expectations and perceptions,

trying to show in a concrete way "you"? The self-portrait can contribute in the process of identity construction? The overall objective is to develop a study on the self-portrait to the practice of identity construction developing observation and sensitivity of the eyes relative to each other in visual arts education. In chapter two entitled "Concept and context" are some important definitions on the picture and the self-portrait in art history, such as concepts and historical context, and discorrermos on the self-portrait as a practice of identity construction. In chapter three "self-portraits under study: self-

representation, duality, multiplicity and illusion" analyzed the self-portraits of the Dutch artist Rembrandt production in order to try to understand this genre and explore it to see if this practice can assist in the search for identity construction. In the fourth chapter entitled "The practice of selfportrait: a moment of reflection and construction of identity" present some self-portraits made in the workshops and brief accounts of the participants. We consider the self-portrait as the expressive form

of the image, representation, presentation, expression and knowledge of himself to himself. The analysis categories were: do (poetic production process and constitution / affirmation of the identity of the subject), the state (meaning, significance, presentation and representation), the visual elements and the personal accounts of the subject (self-knowledge). Here we take art as a social space subjectivities

builder. The individual when autorretratar organized his thoughts, his feelings, in order to give meaning to your image. It is a complex process that involves thinking, express, interpret, create and communicate.

Keywords: Self-portrait. Identity. Rembrandt.

\section{Introdução}

A presente pesquisa tem como tema "Imagens de si: o autorretrato como prática de construção da identidade". Nela buscamos conceituar o retrato e o autorretrato além de discorrermos sobre o autorretrato como prática de construção da identidade. Apresentamos também as produções de um artista conceituado dentro desse gênero: Rembrandt. A arte também pode contribuir para o processo de construção da identidade, podemos usá-la como meio de autoconhecimento. Por meio de um processo criativo de experimentação o individuo pode compreender melhor sua autoimagem, suas limitações, valores e sensações.

O ambiente escolar pode ser um lugar apropriado para se trabalhar questões referentes à percepção e construção de um processo identitário. Ao desenvolvermos atividades que estimulem o processo de exploração de si mesmo proporcionaremos que o individuo identifique e demonstre suas próprias características e percepções, buscando explicitar de forma concreta seu "eu". O autorretrato sempre acompanhou o ser humano em seu desejo de registrar a própria existência e foi tomando formas diferentes no decorrer do tempo, mas sempre foi visto como uma busca de si mesmo. Durante a produção de um autorretrato 


\section{EDUCAÇÃO, ARTES}

VOLUME 11, NÚMERO 1, Ano 2015

E INCLUSÃO

ISSN 1984-3178

passamos por um momento de autoanálise e assim podemos nos reencontrar nesse constante processo de construção e busca da identidade.

Passamos pela infância e pela adolescência até a fase adulta, sempre sendo desafiados pelos novos eventos de nossa vida, como as mudanças físicas, psicológicas, sociais, desenvolvimento de responsabilidades, construção de valores pessoais. O processo de encontrar sentido em nós mesmos nos acompanha em todas as fases de nossas vidas. Sabemos que para alguns os momentos de transição são difíceis e custosos e que a construção da identidade pessoal se dá na relação de um indivíduo com outros indivíduos, em um contexto social. Sendo assim a identidade pessoal pode ser compreendida como um objeto a ser conhecido.

Acreditamos ser possível ir em busca de nossa identidade produzindo autorretratos. Pois acreditamos que podemos revelar algo mais profundo do que nossa própria imagem. Na escola a prática de autorretratos como um procedimento pedagógico no ensino de arte pode contribuir para que o aluno aprimore a capacidade de observação e sensibilidade do olhar em relação a si próprio. A identidade pessoal tem muito a ver com autoestima também. Quando uma pessoa se vê muito diferente do que as outras pessoas a veem ou quando não está em harmonia com as pessoas à sua volta podem experimentar um sentimento de batalha interior para se tornar apreciado pelos outros. Um aspecto importante da autoestima é saber quem somos e quem acreditamos ser. Desta forma, podemos buscar nosso aperfeiçoamento pessoal, para nos tornarmos pessoas cada vez melhores, não no sentido físico, mas no sentido daquilo que idealizamos.

Nesse sentido a presente proposta tem como objetivo geral desenvolver um estudo sobre o autorretrato como prática da construção da identidade desenvolvendo a observação e sensibilidade do olhar em relação a si mesmo no ensino de artes visuais. Para se chegar ao objetivo geral, na pesquisa desenvolveram-se os seguintes objetivos específicos: estudar o autorretrato enquanto gênero artístico, compreendendo-o como prática para a construção da identidade; analisar a produção do artista Rembrandt, apresentando os diferentes modos de produção da imagem de si mesmo; realizar uma intervenção artística (pesquisa de campo) produzindo autorretratos; refletir sobre os efeitos da ação artística trazendo contribuições para pensar o ensino das artes visuais no contexto atual. 


\section{EDUCAÇÃO, ARTES}

As perguntas que nortearam essa pesquisa são as seguintes: A prática de produção de autorretratos pode auxiliar na busca da construção da identidade? Por meio da intervenção artística feita em forma de pesquisa de campo será possível levar ao outro a oportunidade de passar por um processo de autoanálise? O que será possível concluir disso tudo? Essa pesquisa traça algumas reflexões a partir dessas questões.

No presente artigo, a metodologia de pesquisa adotada para seu desenvolvimento corresponde ao levantamento bibliográfico com base em materiais convencionais, como livros, artigos, teses e dissertações, a qual se expandiu também para a busca de dados disponíveis nas redes eletrônicas. Após esse estudo fizemos uma pesquisa de campo organizada em forma de oficina e dividida em dois encontros realizados nos dias 16 e 17 de setembro de 2014, totalizando 10 horas. O universo de estudo abrangeu um grupo de 15 pessoas, com idades entre 09 e 64. Para análise dos dados optou-se por uma pesquisa qualitativa. A pesquisa qualitativa é uma promissora possibilidade de investigação, pois não buscamos enumerar nem medir eventos estatisticamente. Nosso foco é mais amplo e parte da obtenção de dados descritivos mediante contato direto e interativo com os participantes de nossa pesquisa de campo. A identidade neste estudo é tratada num contexto sociocultural, privilegiando as dimensões pessoal e social dos sujeitos. A dimensão pessoal está relacionada à dimensão social. Todo indivíduo além de fazer parte de um grupo social, convive diariamente com outros grupos, construindo assim sua identidade. Nesse intercâmbio relacional com a família, os amigos, a escola, o trabalho, o individuo desempenha papéis diferentes e assim toma consciência de sua unicidade.

Hall (2000), ao analisar como as identidades são construídas, aponta que elas são formadas via comparação com outras identidades, ou relacionadas às diferenças. De acordo com o autor a análise dessas oposições é fundamental para a compreensão do processo de construção cultural das identidades.

Segundo Silva (1995),

A identidade não é essência; não é um dado ou fato - seja da natureza, seja da cultura. A identidade não é fixa, estável, coerente, unificada, permanente. A identidade tão pouco é homogênea, definitiva, acabada, idêntica, transcendental. A identidade é uma construção, um efeito, um processo de produção, uma relação, um ato performativo. A identidade é instável, contraditória, fragmentada, inconsistente, inacabada. O outro é o outro gênero, outra cor diferente, outra sexualidade, outra raça, outra nacionalidade, outro corpo diferente. (p. 97) 


\section{EDUCAÇÃO, ARTES}

VOLUME 11, NÚMERO 1, Ano 2015

E INCLUSÃO

ISSN 1984-3178

O resultado final de nosso trabalho foi um rico material, uma diversidade de autorretratos que nos mostram que a identidade não é algo fixo e imutável. Analisando as produções percebemos que a autorrepresentação de nossos sujeitos de pesquisa foi se alterando dentro de um processo de construção, transformação e afirmação da identidade. Nas oficinas eles puderam mostram como são, como se veem, como se imaginam, como pretendem ser. Numa visão real ou idealizada de si.

\section{Conceituação e Contexto}

\section{- Retrato}

A palavra "Retrato" é um termo vindo do Latim, retratctus, particípio do verbo retrahere que significa "tirar para fora", "copiar". O retrato é a "representação de uma figura individual ou de um grupo, elaborada a partir de modelo vivo, documentos, fotografias, ou com o auxílio da memória; o retrato tem seu sentido primeiro ligado à ideia de mimese (do latim retrahere, copiar)",3

O retrato desempenha um importante papel na história da arte. Apesar das muitas mudanças ao longo da história, esse gênero conseguiu adaptar-se a cada época devido aos artistas estarem abertos a novos aprendizados, novos conceitos, aliando o seu estilo próprio ao gosto da clientela.

O desejo de ter sua imagem retratada surgiu ainda na antiguidade e não estava ao alcance de todos, apenas ao alcance de quem tinha algum tipo de status, ser, por exemplo, um benfeitor da igreja como afirma Gombrich (entre 1379 e 1386) na catedral de Praga. Representam benfeitores da igreja (...) não há por que duvidar. "São retratos autênticos" Além dos benfeitores da igreja também foram retratados governantes e poderosos. E mais tarde, comerciantes e banqueiros passaram a integrar a galeria de retratos na história da arte. De acordo com Sant'Anna (2010, p. 06), "nos séculos XVI e XVII, os grandes pintores se especializaram em pintura de retratos para servir aos governantes"

Segundo Azara (2002),

\footnotetext{
3 In: Enciclopédia de arte online do Instuto Itaú Cultural. Acesso em: Janeiro de 2014.
} 
Os retratados mantêm algo mais que a lembrança esfumaçada do modelo. De algum modo, eles mantêm viva sua presença: conservam e protegem sua presença viva que se percebe sempre através de seu olhar iluminado. (...) Um bom retrato é inconfundível: manifesta os traços pessoais de um determinado indivíduo, traços que não querem dizer, curiosamente, que a imagem deva necessariamente parecer fisicamente ao modelo. deve, antes de tudo, evocar o modelo espiritualmente, permitindo que ele se manifeste através da obra perante os sentidos do espectador. (AZARA, 2002, p. 13-14)

$O$ retrato já era considerado um gênero independente no século XV e tornara-se a possibilidade por excelência de representar a personalidade do modelo e o seu nível social. Desse modo, o retrato emoldura a individualidade, tanto do artista como do modelo retratado.

Embora os retratos possam mostrar uma imagem distorcida, ideal ou parcial da imagem do modelo, o retrato como gênero de pintura é, historicamente, ligado à ideia de mimesis que de acordo com o dicionário etimológico vem do grego e significa imitação. Já no século XIX e XX as pesquisas das vanguardas sobrepunham abstração à semelhança física no retrato. Após a Segunda Guerra, a retratística toma importância através de Lucian Freud, cujo trabalho volta a ter a preocupação de possuir uma identidade com o retratado. (West, 2004) ${ }^{4}$

Acreditamos que, ao retrato será sempre atribuído o papel de substituto do seu referente. Variando de caso para caso, do teor da mensagem desejada e transmitida, este gênero de imagem pode funcionar como substituto afetivo, político, social e psíquico.

\section{- O Autorretrato}

O autorretrato é um subgênero do retrato e pode ser definido como uma imagem representativa da individualidade de seu autor; assim como o retrato genérico, busca revelar particularidades do retratado, valorizando sua singularidade, em detrimento do típico. No sentido clássico do termo, o retrato, independentemente de refletir características do próprio autor ou de um modelo externo, buscará caracterizar seu objeto de investigação, evocando e ressaltando particularidades do mesmo, de forma a recortá-lo do contexto. Desta forma, o

\footnotetext{
${ }^{4}$ WEST, Luise. Retratos familiares: In Memorian. São Paulo, 1998. In CARVALHO, Saul Ferdinando de Oliveira. Retratos: entre as Cores e a materialidade. Dissertação apresentada ao Instituto de Artes da Universidade Estadual de Campinas. 2010.
} 
autorretrato seria uma representação da individualidade do próprio autor, e, portanto, pressupõe-se que funcione como uma reflexão sobre o universo particular do mesmo.

A consolidação do autorretrato no meio artístico, a partir do Renascimento, pode ter acontecido em decorrência do afastamento entre a atividade artística e os preceitos religiosos, valorizados no período medieval; assim, o ser humano e a noção de indivíduo tornam-se focos crescentes das preocupações sociais e do imaginário dos artistas. Por esse motivo, desde então, o retrato e o autorretrato passaram a ser amplamente produzidos pictoricamente de maneira realista ou idealizada, inclusive porque o advento da fotografia não havia ocorrido.

Mas, porque deixar sua imagem gravada para o futuro? Ora, a imagem pode prolongar e manter algo vivo, recorda Moles (1976) e Rahde (2000) ${ }^{5}$, quando estes autores dizem que a imagem é a tentativa do homem de reter, cristalizar pela permanência, um aspecto visual. Sendo então registro, a imagem, e neste caso a imagem de si próprio, tem a função de registrar, gravar para o futuro algo referente ao próprio artista, uma forma de se fazer lembrar, ser notado, observado, indicar seus gostos, ações, padrões de comportamento, atitudes, status.

Os artistas começaram a pintar seus próprios rostos. Isso porque eles também queriam: deixar sua imagem gravada para o futuro; sentir que eram importantes como pessoas humanas e como profissionais; expressar em suas pinturas o que sentiam internamente, suas emoções e seus pensamentos; usar suas próprias imagens como pretextos para elaborar obras de arte, cuidando das cores, das pinceladas, dos contornos, das texturas. (CANTON, 2001, p. 05)

O autorretrato pode servir como uma forma rudimentar de autopromoção. Observando bem, percebemos que os artistas buscavam um diferencial, uma marca pessoal que lhes diferenciasse e os tornasse reconhecidos. Alguns usavam a prática do autorretrato para expressar seus sentimentos interiores, seus pensamentos, provocando sensações no espectador, outros o faziam como meio de exercitar e aprimorar suas técnicas e habilidades como, no desenho e na pintura, ou ainda usavam suas imagens com o objetivo de com ela elaborar obras de arte, trabalhando com atenção as cores, as texturas, etc.

Com o advento da modernidade, a identidade, que parecia fixa e estável foi abruptamente deslocada pela experiência do mutável. Hall ${ }^{6}$, em seu livro A identidade

\footnotetext{
${ }^{5}$ In SCHUH. Cátia Inês. A prospecção pós-moderna da comunicação visual no imaginário de Frida Kahlo. Tese apresentada para obter o grau de doutor, pelo Programa de Pós-Graduação em Comunicação Social da PUC do Rio Grande do Sul.

${ }^{6}$ HALL, Stuart. A identidade cultural na pós-modernidade. 10 ed. Rio de Janeiro: DP\&A Editora,2005. In: ABREU, Simone Rocha. Autorretrato: inventando a si mesmo. Artigo apresentado a USP.
} 


\section{EDUCAÇÃO, ARTES}

VOLUME 11, NÚMERO 1, Ano 2015

E INCLUSÃO

ISSN 1984-3178

Cultural na Pós-modernidade, analisa mudanças históricas que fizeram com que a questão identitária, vista no Renascimento como linear, se tornasse mutante no contexto atual, sendo visto como importante neste processo o advento da modernidade e que durante o século XX houve um processo contínuo de descentralização do indivíduo, deixando o indivíduo moderno fragmentado.

Segundo Strickland ${ }^{7}$ (1999), os autorretratos tradicionais - aqueles produzidos antes do período moderno - se destacam por refletirem a iconografia da época: o uso do óleo sobre tela, a perspectiva, a luz e a sombra e a configuração em pirâmide. Este efeito somente foi superado em precisão de detalhes pela fotografia.

A época que segue o Renascimento traria dele a vontade de mudar, de romper com o passado tradicional. Este desejo de diferenciação e de inovação se refletiu na iconografia da época, resultando numa série de movimentos artísticos que romperiam com a visão tradicional da imagem e mudariam para sempre a visualidade do homem.

Os modos de produção artística do autorretrato começam a se transformar, de maneira mais visível, a partir das modificações sociais e tecnológicas ocorridas na segunda metade do século XIX, responsáveis pelo advento fotográfico, o qual alterou o modo com que o sujeito visualiza o mundo e a si mesmo. A fotografia possui capacidade de reproduzir com suposta exatidão o que é visto pelo olho. Dessa forma, abre novos caminhos à pintura, cujo resultado consiste nas vanguardas modernas, representadas por artistas de variadas nacionalidades, os quais, em sua grande maioria, produziram, além de outros tipos de trabalhos, autorretratos. Tais artistas desenvolveram deformações e ênfases formais que afastavam o autorretrato da realidade física, mas serviam para demonstrar a expressividade e a singularidade do artista, valorizados na arte moderna.

Nos autorretratos modernos, a representação da imagem não importa como objeto, mas como um ato, algo a ser comunicado. $\mathrm{O}$ artista pode liberar sua imaginação sem obrigações artísticas e morais, revelando assim uma identidade cambiante, mutável e fragmentada.

\footnotetext{
${ }^{7}$ In SCHUH, Cátia Inês. A prospeção pós-moderna da comunicação visual no imaginário de Frida Kahlo. Tese apresentada para obter o grau de doutor, pelo Programa de Pós-Graduação em Comunicação Social da PUC do Rio Grande do Sul.
} 


\section{EDUCAÇÃO, ARTES}

VOLUME 11, NÚMERO 1, Ano 2015

E INCLUSÃO

ISSN 1984-3178

Observando os autorretratos contemporâneos percebemos que, em grande parte da produção, o artista não está preocupado com a aproximação de seu autorretrato com sua semelhança física. Ao contrário, percebemos que ele oculta sua aparência física, forja outras identidades, distanciando-se da vaidade, da ilusão das aparências e da superficialidade. Nesse sentido, muitas vezes, a imagem produzida não revela a identidade do sujeito retratado.

Diferentemente do autorretrato produzido ao longo da história, os artistas contemporâneos atribuem-lhe novos conceitos, novos sentidos, construindo-o não mais com a intenção de, simplesmente, copiar a sua aparência física, mas como forma de questionar sua identidade.

A ideia de autorretrato, como sinônimo de veracidade, é questionada por muitos artistas, pois, mesmo diante de um autorretrato produzido com base na imagem do artista refletida em espelhos, nos depararemos com uma imagem verossímil do retratado. Tal afirmativa é coerente com as concepções de Fabris $(2004)^{8}$, a qual menciona que o espelho parece revelar ao indivíduo sua própria identidade, mas, ao mesmo tempo, confronta-o com a evidência de que a unidade do "eu" é ilusória. Em razão dessa evidência, frente ao espelho, é criada no sujeito uma cisão entre o indivíduo refletido na superfície especular e o sujeito que percebe essa imagem. Assim, para Fabris, o espelho coloca em crise a crença numa identidade unitária e transforma-se num objeto de conhecimento, fazendo com que o sujeito seja capaz de pensar sobre a relação existente entre seu "eu" e a própria imagem refletida.

Afinal, nosso rosto, assim como nossa identidade, está constantemente sofrendo mudanças. Mudanças relacionadas com a idade, com as emoções, com os fatores aos quais estamos expostos. Ou seja, naturalmente nos colocamos numa condição de estarmos sempre em processo de nos tornar alguém. Ao olharmos para o espelho pensamos ter captado nossas feições no reflexo, porém essas feições já se transformaram empurrando nosso "eu” para um futuro. Por isso, em alguns momentos, temos dificuldade de nos reconhecer.

Ao abordar práticas contemporâneas de autorretratos, Canton (2004), salienta a inclinação dos artistas para "brincarem" com a própria imagem. Dessa forma, o artista projeta-se no autorretrato com liberdade para fazê-lo como desejar.

\footnotetext{
${ }^{8}$ In PEREZ, Karine Gomes. Autorretratos contemporâneos: revelando uma “identidade-idem” ou subvertendo a lógica do espelho?. Artigo apresentado na UFSM.
} 
Acreditamos que independente do meio escolhido para a produção do autorretrato, o indivíduo terá se refletido em suas dimensões físicas, cognitivas, emocionais, sociais, éticas e estéticas. O autorretrato constitui-se uma forma de afirmação da presença, por meio dele o individuo representa o que ele é, imagina, deseja ou idealiza ser.

\section{- O Autorretrato e a Prática de Construção da Identidade}

Já dizia Hall (2000, p. 12)

O sujeito, previamente vivido como tendo uma identidade unificada e estável, está se tornando fragmentado; composto não de uma única, mas de várias identidades, algumas vezes contraditórias ou não resolvidas.

O homem começou a se desvincular da identidade social já no início da Era Moderna e hoje se mostra consciente da complexidade e da profundidade de sua individualidade. Encontramos, hoje, um indivíduo capaz de se autoanalisar e distinguir-se dos demais, ciente de que sua identidade pessoal está sujeita a constantes transformações.

O indivíduo que conhece a flexibilidade de sua identidade consegue até manipular a própria imagem, e adquire capacidades de criar máscaras que facilitam sua vivência dentro de alguns grupos.

A ação de se autorretratar é suscetível de novas versões, não podemos falar de um ser inteiro, completo, acabado. A própria vida é uma série de identificações e será por meio delas que o sujeito se constituirá, construindo assim sua identidade. Acredita-se que nesse processo algumas identidades são impostas socialmente ou que acreditamos estar escolhendo.

Bauman (2005) fala que a identidade, no mundo atual, está esfacelada, tudo é ilusório e construído de forma a acreditarmos pertencermos a alguma coisa, buscando conquistar bens e status.

As identidades flutuam no ar, algumas de nossa própria escolha, mas outras infladas e lançadas pelas pessoas em nossa volta, e é preciso estar em alerta constante para defender as primeiras em relação às últimas (BAUMAN, 2005, p. 17)

Isso demonstra que o processo de construção da identidade é uma missão complexa, pois nunca estamos muito certos de quem somos realmente. A identidade não é algo a ser descoberto, não é alvo de conquista, mas sim algo a ser constantemente construído, afirmado. A identidade nada mais é que um processo de criação vinculada a interioridade do sujeito. Assim, como uma construção imaginária, a identidade é passível de alterações, construções, 


\section{EDUCAÇÃO, ARTES}

VOLUME 11, NÚMERO 1, Ano 2015 E INCLUSÃO

reconstruções e desconstruções. E ciente dessas possibilidades, através da prática do autorretrato podemos ir de encontro a novas imagens de nosso "eu" que nos identifiquem como cidadãos. Um cidadão capaz de reconhecer sua identidade.

Trabalhar a questão da identidade é, sempre, válido em qualquer faixa etária, pois estamos sempre nos construindo, nos modificando. Ao trabalhar o autorretrato fundamentado na percepção, através da observação, com momentos de reflexão sobre o que somos ou fomos a cada momento de nossas vidas estaremos oferecendo condições para que o indivíduo compreenda sua própria condição e de suas escolhas. Refletir sobre todo esse processo pode gerar conhecimento e assim contribuir para o processo de construção de sua identidade.

\section{Autorretratos em Estudo: autorrepresentação, Multiplicidade e Ilusão}

Dentre diversos artistas renomados na prática de autorretratos escolhemos o holandês Rembrandt porque ele foi o artista que mais se autorretratou na história da arte, pois buscava se aperfeiçoar no desenho, na gravura e na pintura. Durante muitos séculos, os artistas ganharam a vida pintando retratos, e alguns ainda hoje o fazem. Os retratos são populares por duas razões: os retratados gostam de ter suas fisionomias registradas para a posteridade e aqueles que apreciam quadros gostam de descobrir que aparências tinham as pessoas do passado. Não é diferente com a prática do autorretrato, desde muito tempo aos dias atuais inúmeros artistas exploram seus rostos a fim de materializar sua identidade. E, os objetivos são os mais diversos, desde um simples exercício para aperfeiçoar seus traços e assim deixar cada vez mais realista os retratos e autorretratos produzidos, como fazia Rembrandt, até a expressão de dores e alegrias numa incessante busca de si.

\section{- REMBRANDT van RIJN}




\section{EDUCAÇÃO, ARTES

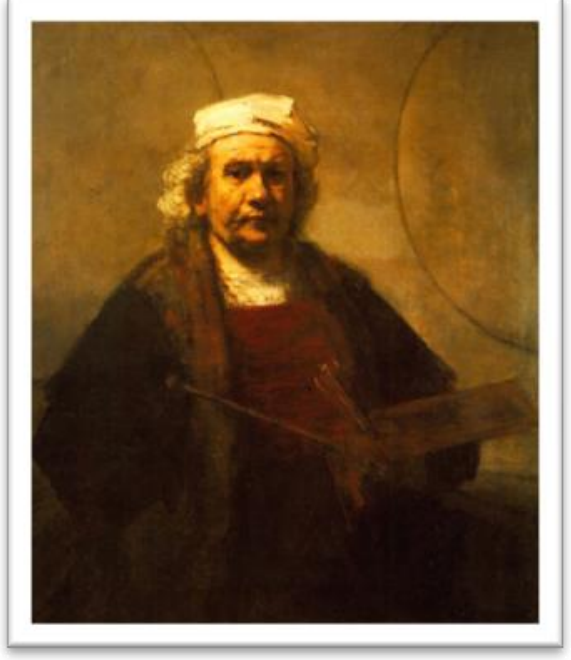

Figura $^{9} 01$ - Autorretrato, 1661 - Rembrandt van Rijn

Em se tratando de autorretratos, Rembrandt van Rijn (1606-1669) merece destaque especial, pois foi o artista que mais se autorretratou. Além do grande número de retratos realizados, o artista retratou-se nos diferentes períodos de sua vida (juventude, maturidade e velhice) marcando as diferentes leituras que fazia de si mesmo ao longo dos anos. Pintor flamengo ${ }^{10}$ nascido em Leiden, Países Baixos ${ }^{11}$, mestre do claro-escuro é considerado um dos maiores pintores do Ocidente. Tornou-se o principal representante do barroco protestante do norte da Europa e pintou imensa série de retratos, muitos dos quais de rabinos e outros judeus. Após a morte de sua esposa, sua arte sofreu grandes mudanças e essas alterações diminuíram sua popularidade, porém o nível de sua arte não, e iniciou sua fase mais produtiva, essa época marca uma etapa importante em sua vida, pois produziu numerosos autorretratos que o levaram a um de seus pontos culminantes na história da arte.

Rembrandt pintou em sua carreira dezenas de autorretratos, que serviram como sua propaganda como um pintor de retratos, e também como uma forma de estudo de expressões

\footnotetext{
${ }^{9}$ Figuras retiradas da internet.

${ }^{10}$ Os artistas flamengos são considerados os precursores da pintura de gênero (temas mais íntimos, que se aproximam da vida e da experiência cotidiana).

${ }^{11}$ Como artistas dos países baixos, buscavam outras possibilidades para a pintura do barroco, uma vez que estavam em região protestante. Assim o retrato foi uma importante possibilidade para os estudos em pintura.
} 


\section{EDUCAÇÃO, ARTES}

VOLUME 11, NÚMERO 1, Ano 2015

faciais e exteriorização de suas expressões. Podemos dizer que o interesse do artista em se autorretratar era aprofundar seus estudos em se tratando de desenho, pintura, gravura.

Conforme Canton (2004, p. 10), "ele deixou imagens para o mundo, desde a de um jovem de 23 anos até a de um senhor rechonchudo, de cabelos brancos e pele marcada, em seus últimos dias de vida". Em várias etapas de sua vida, representou a si mesmo, mostrandose desde o jovem promissor até o velho falido. Em algumas obras, autorretratou-se junto de sua primeira esposa, Saskia (figura 02). Muitas de suas obras têm caráter mais pessoal do que comercial, algumas nem foram comercializadas.

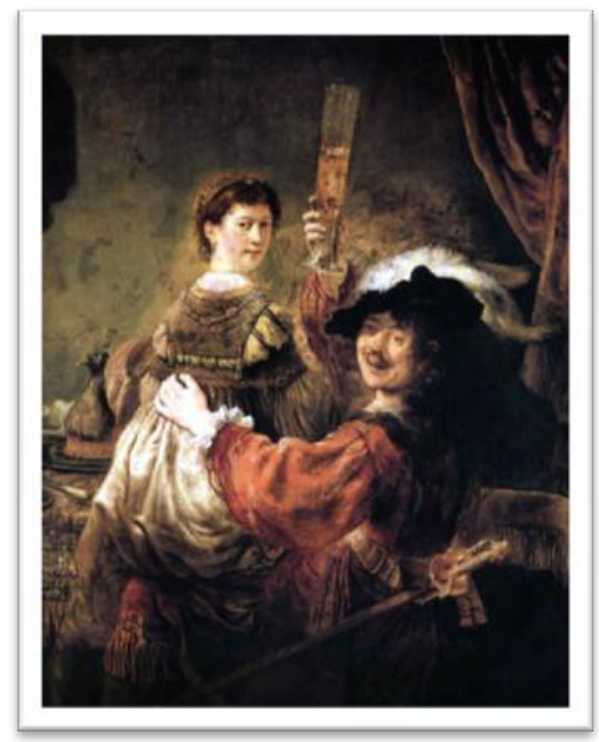

Figura 02 - Autorretrato com Saskia (1635)

Rembrandt, segundo algumas fontes, teria pintado alguns quadros com extrema agilidade, como um autorretrato que ele executou em um dia, enquanto outros ele executava em meses (Tümpel ${ }^{12}$, 2006, p. 168). O fato de Rembrandt ter feito um autorretrato em um dia é uma prova incontestável da habilidade do pintor.

O pintor holandês é célebre pelas imagens de si mesmo nos mais diversos suportes. Analisando-as podemos perceber que o artista gostava de se retratar nas mais diversas

\footnotetext{
${ }^{12}$ TÜMPEL, Christian. Rembrandt - images and metaphors. London: Haus Publishing, 2006. In: CARVALHO, Saul Ferdinando de Oliveira. Retratos: entre as cores e a materialidade. Dissertação apresentada ao Instituto de Arte. Campinas: 2010.
} 


\section{EDUCAÇÃO, ARTES \\ VOLUME 11, NÚMERO 1, Ano 2015 \\ E INCLUSÃO

situações, com as mais variadas expressões, até mesmo na vertente de autorretrato como o outro. Segundo Fonseca ${ }^{13}$ em artigo apresentado a UNICAMP:

É sabido, por exemplo, através de seu inventário, que o artista era possuidor de trajes orientais, além de guardar também vestuários relativos ao Renascimento na Itália. A partir dessas fontes in loco e, claro, também a da movimentação de retratos famosos pintados por Rafael e Tiziano, Rembrandt conseguia transformar-se em outros, através da inclusão de sua efígie. (figura 03).

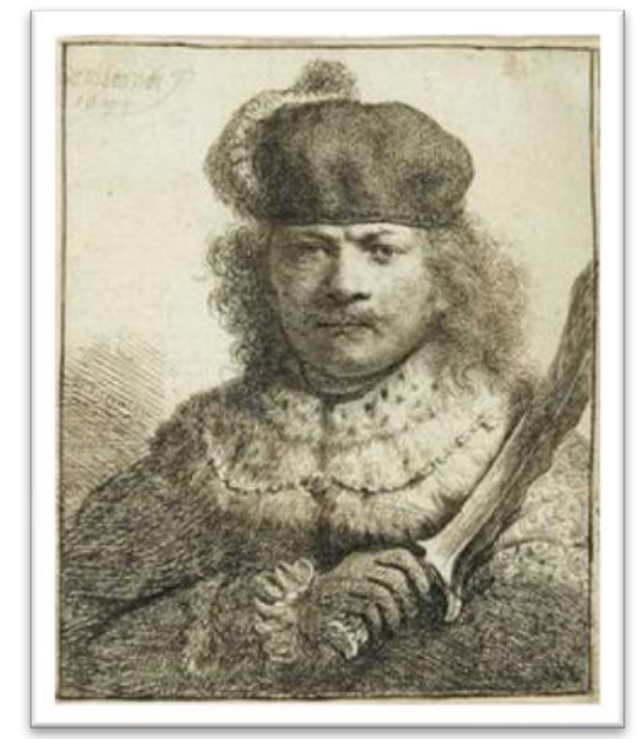

Figura 03 - Autorretrato como oriental,1634

Em suas obras não revela apenas as mudanças que a vivência trouxe ao seu aspecto físico, mas essencialmente ao seu espírito interior. Podemos deduzir que, em seus autorretratos, Rembrandt expressa emoções ou situações cotidianas por ele vividas.

A pintura de Rembrandt sempre foi referencia a muitos artistas posteriores à sua época. Suas características mais marcantes são a profundidade psicológica e seus empastos de tintas, colocados pontualmente, criando efeitos de profundidade e força.

Segundo Tümpel (2006), Rembrandt preferia que seus quadros fossem vistos a certa distância, não à proximidade como era comum até então. O Autorretrato jovem de 1628 (figura 04) é um dos primeiros autorretratos do artista, foi pintado aos 22 anos. Nessa obra,

\footnotetext{
${ }^{13}$ FONSECA, Raphael. Mestre em História da Arte pela UERJ em seu artigo apresentado a UNICAMP: Retrato e autorretrato em Nikki S. Lee.
} 


\section{EDUCAÇÃO, ARTES}

VOLUME 11, NÚMERO 1, Ano 2015

ele se coloca na imagem envolto por uma sombra, com a luz incindindo em si apenas no pescoço, e parte da face, além do fundo. Alguns consideram essa obra como sendo um estudo onde o pintor teria experimentado luzes e sombras além de aplicações de tinta.

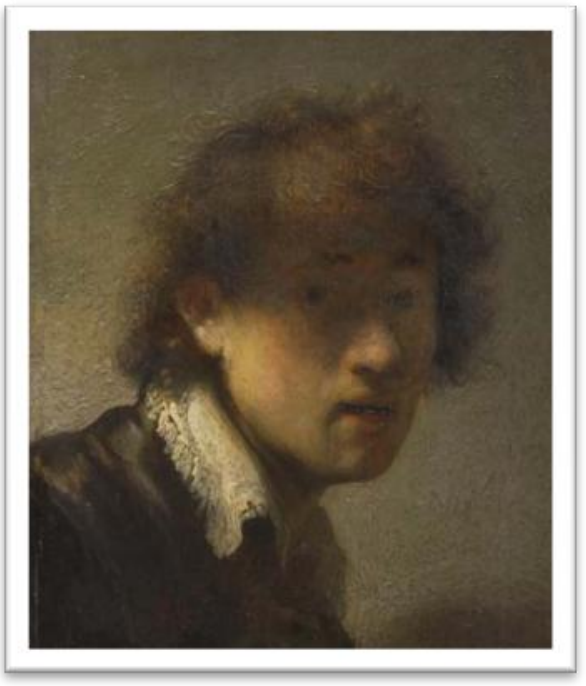

Figura 04 - Autorretrato jovem, Óleo sobre painel, 1628.

Rembrandt explorou com muita intensidade a profundidade psicológica e a ênfase no olhar. Sua técnica é fonte de discussões em nossos dias. Os efeitos únicos de suas pinceladas marcadas e volumes de tintas conseguidos para criar efeitos visuais não são até hoje explicados com precisão, pois não há fonte de referencia conhecida, como textos da época e manuscritos que falem do processo de pintura desse artista. (Carvalho ${ }^{14}, 2010$, p. 16)

Seus autorretratos representam uma espécie de diário e percorrendo a série de autorretratos que produziu podemos perceber que, além das diferentes idades do artista, Rembrandt retrata diversas situações, expressões, sentimentos, por vezes até seu caráter é revelado. Na figura 05 o artista aparece apoiado em um corrimão, aparenta mais velho e sua expressão é mais fechada, sua pose de frente ao expectador e com o braço apoiado na grade tem provável influência de seus estudos sobre dois mestres italianos Rafael e Ticiano ${ }^{15}$. O artista encontrou em seu próprio rosto um tema móvel e dócil, pleno de emoção e sobre o qual

\footnotetext{
${ }^{14}$ CARVALHO, Saul Ferdinando de Oliveira. Retratos: entre as cores e a materialidade. Dissertação de mestrado. Campinas, 2010.

${ }^{15}$ Fonte: http://www.rembrandthuis.nl/
} 


\section{EDUCAÇÃO, ARTES \\ VOLUME 11, NÚMERO 1, Ano 2015 \\ E INCLUSÃO \\ ISSN 1984-3178}

exercia tal domínio que poderia alterar, deformar e abstrair como quisesse. (Vançan, 2003, p. 22)

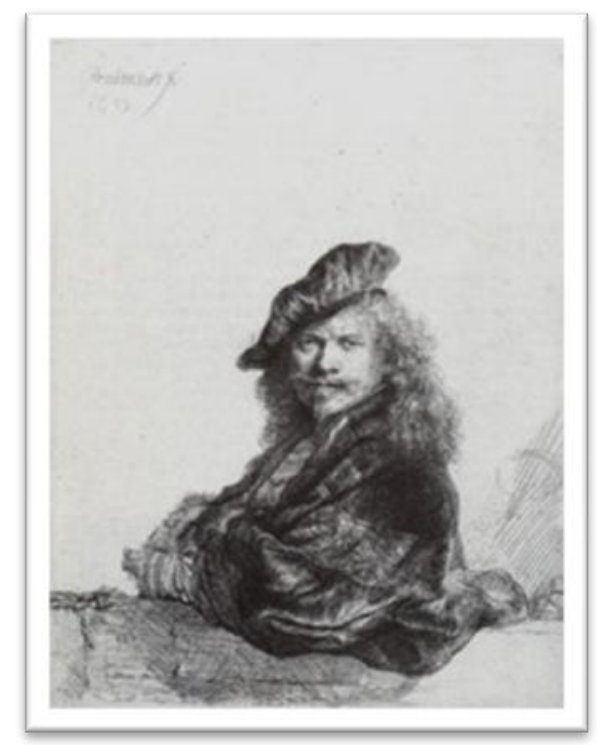

Figura 05 - Autorretrato apoiado em um corrimão

$\mathrm{Na}$ gravura de 1636, intitulada Autorretrato com Saskia (figura 06), Rembrandt autorretrata-se com a presença de uma figura feminina, que alude à companheira, e apesar da feição jovial apresenta uma postura mais séria, em vez de um biquinho e olhar de espanto como certa vez se autorretratou (figura 07). Rembrandt exprimiu uma série de expressões fisionômicas, ora fazendo biquinhos, ora com ar de pintor de respeito. A ausência de pintura de fundo e outros elementos que complementem a composição de muitos autorretratos fazem com que a atenção fique focada no artista não evidenciando o local onde possa ter feito esses autorretratos.

Desde muito cedo Rembrandt estudou a luz para destacar o que lhe era mais significativo em suas obras, seja nas narrativas religiosas, nos retratos, em seus autorretratos ou nas pinturas de gênero. A luz era o instrumento com o qual o artista interpretava a si mesmo e aos outros. 


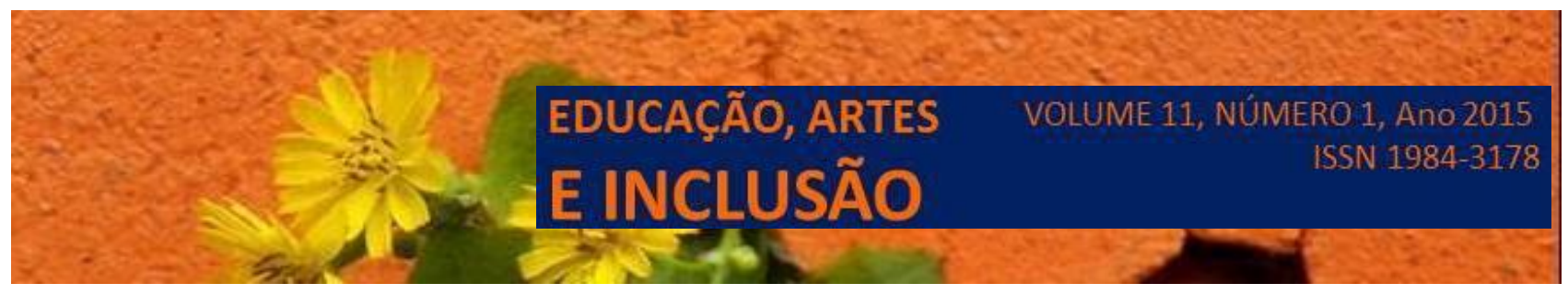

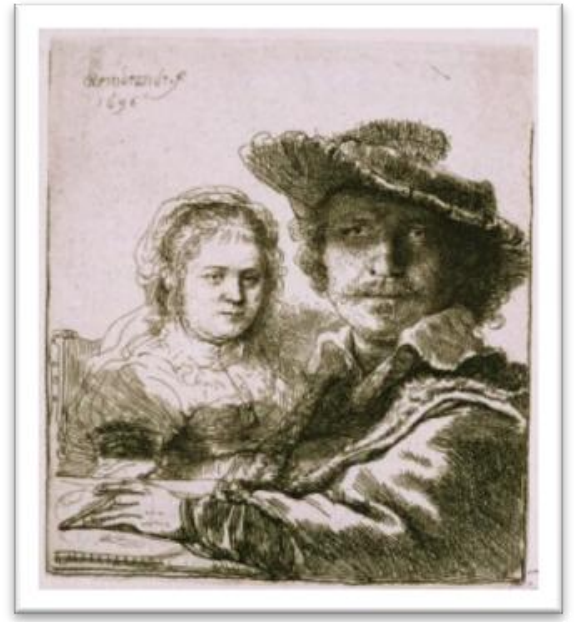

Figura 06 - Autorretrato com Saskia, gravura, 1636

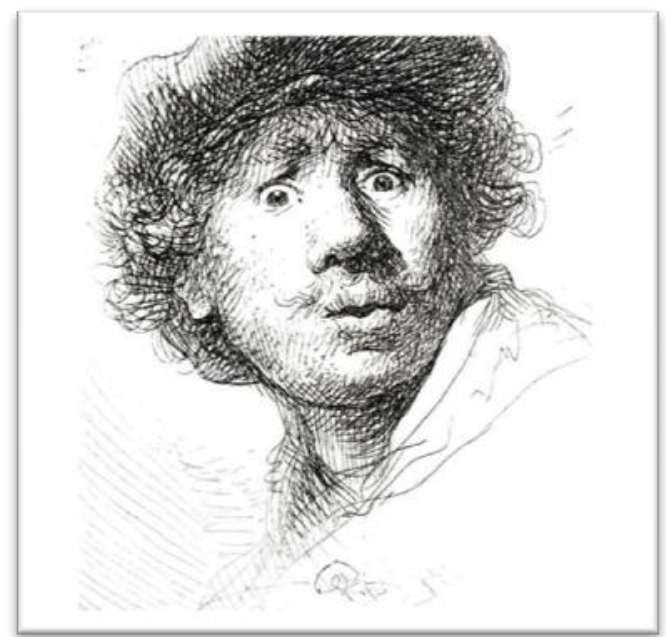

Figura 07 - Autorretrato Rembradt

Observando a obra Autorretrato com 23 anos de 1629 (figura 08) vemos uma figura jovem e ingenuamente vaidosa. A gola da roupa, de característica militar, dá certa formalidade à aparência pessoal. A fisionomia jovial de frente para o espectador e com a metade do rosto iluminado valoriza a postura do conjunto. $\mathrm{O}$ cabelo de Rembrandt apresentase suave nos seus tons castanhos, ganhando especial beleza através dos fios alourados pela luz, formando uma expressiva mecha que pende sobre sua testa. A vivacidade da juventude, com seus desejos e ambições, está contida no olhar confiante do artista. A pintura apresenta um realismo muito admirado pelos holandeses da época. Este autorretrato do início de sua carreira atesta a importância da iluminação em sua linguagem. O contraste entre sombra e luz divide seu rosto em duas partes, formando uma linha invisível que realça a verticalidade da figura. A sombra da cabeça no plano de fundo ressalta a face iluminada e acentua a expressividade do conjunto facial. Os tons terrosos que predominam no quadro, junto com a luz da composição, resultam em um pequeno plano retangular iluminado, para onde a atenção do nosso olhar é concentrada. O olhar percorre a gola branca, passando pelos lábios ligeiramente avermelhados e vai até a mecha loura de cabelos ${ }^{16}$.

\footnotetext{
${ }^{16}$ Fonte: http://www.casthalia.com.br/a mansao/obras/rembrandt autoretrato.html
} 


\section{EDUCAÇÃO, ARTES

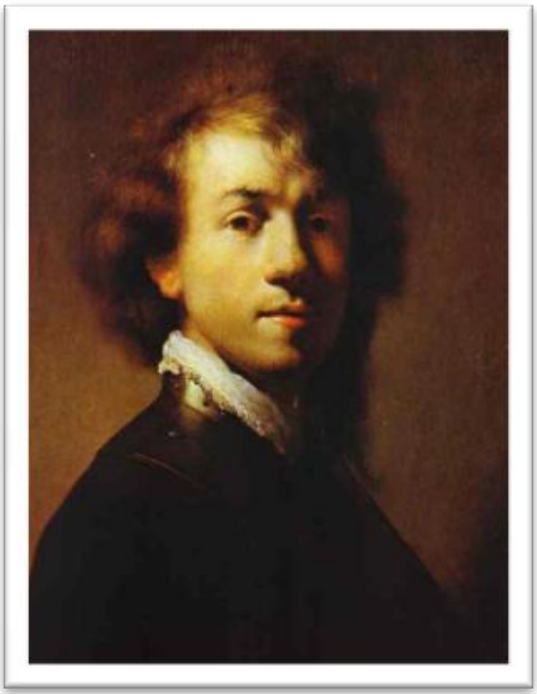

Figura 08 - Autorretrato com 23 anos, 1629, óleo sobre madeira

Seus questionamentos sobre a alma humana se destacam nos retratos que fez de si mesmo. Mesmo jovem ele já intuía que a sua auto-imagem retratada seria o testemunho mais fiel de sua biografia. As pinceladas insinuantes de Rembrandt faziam parte de sua consciência como pintor. E, analisando seus autorretratos percebemos que existe uma diferença entre o Rembrandt jovem e o maduro, quanto ao tratamento da tinta em seus quadros. O jovem Rembrandt trabalha uma pintura mais lisa, à maneira de seu professor, enquanto que o Rembrandt maduro vai gradativamente deixando as marcas do pincel e construindo opticamente certos detalhes de sua pintura. Encontrou sua própria linguagem adicionando mais volume, ou seja, trabalhando com mais tinta, explorando a capacidade do óleo, fazendo uso do empasto. Rembrandt em sua velhice dissolve a realidade concreta na penumbra, a técnica dilui-se, deixando de perturbar o mistério do espírito que se manifesta (Huygue ${ }^{17}$, 1960, p, 428).

\section{A Prática do Autorretrato: um momento de reflexão e construção da identidade}

Neste capítulo são narradas algumas experiências vivenciadas na pesquisa de campo desenvolvida em formato de oficinas com um grupo de pessoas de diferentes idades,

\footnotetext{
${ }^{17}$ HUYGUE, René. A arte e a alma. Paris: Livraria Bertrand, 1960. In CARVALHO, Saul Ferdinando de Oliveira. Retratos: entre as cores e a materialidade. Dissertação de mestrado. Campinas, 2010.
} 


\section{EDUCAÇÃO, ARTES}

VOLUME 11, NÚMERO 1, Ano 2015

E INCLUSÃO

ISSN 1984-3178

moradoras do distrito de Taquara Verde, município de Caçador - SC. As oficinas aconteceram no turno vespertino dos dias 16 e 17 de setembro de 2014, com quatro horas de duração por encontro. O objetivo da pesquisa foi comprovar que podemos trabalhar questões identitárias por meio da autorrepresentação.

A pesquisa de campo se deteve na observação das atitudes e nas respostas dos participantes diante dos questionamentos sobre si. Logo nas primeiras conversas foram abordados temas sobre autoconhecimento. Sobre a experiência de voltar os olhos para si buscando se conhecer melhor. Por meio das representações das obras de Rembrandt os participantes puderam reconhecer as inúmeras possibilidades de construção da própria imagem.

Foi proposto aos participantes que se autorretratassem e para isso foi disponibilizado diversos materiais para que escolhessem o que mais lhes agradassem. Durante essa prática conversávamos sobre identidade, autoestima, sobre a imagem no espelho e assim pudemos perceber, por suas ações e manifestações orais, o quanto se sentiam valorizados e com a autoestima elevada. Utilizamos a arte a fim de proporcionar um momento de materialização da identidade. Identidade essa que está em constante processo de construção e transformação, pois todos, independentes da faixa etária se projetam e idealizam sua própria imagem.

\section{Considerações Finais}

Autorretratar-se é um ato referente à produção da imagem do artista realizada por ele mesmo. Em alguns autorretratos o foco de interesse, está na busca da semelhança física do autor, principalmente nos aspectos do rosto, em outros o foco está na expressividade e na singularidade do artista que se autorretrata não mais com a intenção de copiar sua aparência, mas sim como forma de questionar sua identidade.

Ao retomar as perguntas lançadas na introdução da presente pesquisa, concluímos que as razões que levam os artistas a se autorretratarem são diversas. Os autorretratos do artista renascentista, Rembrandt, mostram sua imagem de modo realista, revelam sua aparência física por vezes idealizada. Suas obras eram sua propaganda como pintor de retratos, e também uma forma de estudo das expressões faciais.

Concluímos também que no processo de execução do autorretrato, ao tornar tocável aquilo que é subjetivo, sendo ela uma identidade idêntica de si mesmo, imutável ou mesmo 
uma identidade múltipla, por vezes contraditória, não importa qual identidade irá retratar, nesse processo certamente o artista acaba conhecendo a si mesmo. Independente de haver coincidência absoluta ou não entre a imagem produzida e a aparência real do indivíduo ao produzir o autorretrato o sujeito em um momento crítico-reflexivo se concentra em si mesmo num processo de autoconhecimento.

Acreditamos que pensar a nossa identidade vai além de simplesmente responder a pergunta "quem sou eu". Falamos da identidade concebida não como algo estático, mas sim como um processo em constante evolução, que necessita de uma constante busca de si mesmo. No decorrer dessa pesquisa concluímos que a prática de produção de autorretratos pode auxiliar na busca da construção da identidade e as análises das produções dos artistas estudados nos mostraram que as experiências artísticas podem contribuir nesse processo de autoconhecimento. Por meio da arte o individuo pode estabelecer uma conexão com o seu "eu" mais profundo e assim trazê-lo à tona por meio do processo criativo, da experimentação e do exercício da imaginação. A compreensão da autoimagem, de suas limitações, valores e sensações são estimuladas no momento em que busca explicitar de forma concreta seu "eu".

A partir da realização da pesquisa de campo e da análise dos dados, concluímos que é possível levar ao outro a oportunidade de passar por um processo de autoanálise, de autorreflexão sobre si mesmo. Através da contextualização do retrato e do autorretrato, bem como do estudo das obras do artista Rembrandt fomentamos a investigação artística e a criatividade do grupo. Diante de uma série de atividades conheceram diferentes possibilidades autorrepresentativas e após momentos de reflexão percebemos que cada participante se encontrou e experimentou, por meio do autorretrato, a captura de seu "eu", construindo ou afirmando assim sua identidade.

Concluímos que podemos ajudar qualquer indivíduo a sentir-se valorizado, ajudando-o a descobrir-se e tornar-se a pessoa que ele deseja ser. As pessoas que realmente gostam daquilo que são e que se aceitam ganham autoconfiança, aumentam a autoestima e assim passam a lidar com falhas, perdas, vergonhas, dificuldades e derrotas. Percebemos isso nos relatos, nas conversas e nos registros escritos pelos participantes os quais nos foram entregue e estão nos anexos desta pesquisa.

Ao desenvolvermos esse trabalho com os autorretratos concluímos também que é possível questionar a imagem refletida no espelho e nas fotografias. Ao finalizarmos a 
pesquisa, percebemos que as representações dos rostos próximos do real desapareceram das composições o que nos indica que os indivíduos perceberam que todos são detentores de várias identidades, de múltiplos "eus". O autorretrato serviu como uma janela, e através dela eles puderam se contemplar olhando-se de dentro para fora. Nesse sentido a presente proposta atingiu seu objetivo geral que era de desenvolver um estudo sobre o autorretrato como prática da construção da identidade desenvolvendo a observação e sensibilidade do olhar em relação a si mesmo no ensino de artes visuais.

A partir da produção dos autorretratos auxiliamos no processo de despertar para a consciencia de si mesmo e de construir ou afirmar sua identidade. Essa busca foi uma tentativa para que pudessem perceber-se como seres individuais, capazes de transformar a si mesmo e o mundo em que vivem, dotados de uma identidade que está em constante construção, e que a arte pode ser companheira nesse processo. O processo de construção da identidade é uma missão complexa, pois nunca estamos muito certos de quem somos realmente. A identidade não é algo a ser descoberto, não é alvo de conquista, mas sim algo a ser constantemente construído, afirmado.

Acreditamos que ao serem motivados a fazerem a leitura dos autorretratos produzidos, proporcionamos a cada participante um processo de autorreflexão construindo/afirmando assim sua identidade.

\section{REFERÊNCIAS}

AZARA, Pedro. El ojo y la sombra: uma mirada al retrato em occidente. Barcelona: Editorial Gustavo Gilli, Sl, 2002. In CARVALHO, Saul Ferdinando de Oliveira. Retratos: entre as Cores e a materialidade. Dissertação apresentada ao Instituto de Artes da Universidade Estadual de Campinas. 2010.

BAUMAN, Zygmunt. Identidade. Zahar, Rio de Janeiro, 2005.

CANTON, Kátia. Espelho de artista. 2 ed. São Paulo: Cosac \& Naify, 2001. , Kátia. Novíssima arte brasileira: um guia de tendências. São Paulo: Iluminuras, 2001

CARVALHO, Saul Ferdinando de Oliveira. Retratos: entre as cores e a materialidade. Dissertação de mestrado. Campinas, 2010. 


\section{EDUCAÇÃO, ARTES}

VOLUME 11, NÚMERO 1, Ano 2015

E INCLUSÃO

ISSN 1984-3178

FABRIS, Annateresa. Identidades virtuais: uma leitura do retrato fotográfico. Belo Horizonte: UFMG, 2004.

Annateresa. O artista como produtor: Andy Warhol e o pós-moderno. In:

CHALHUB, S. (org.) Pós-moderno \& artes plásticas, cultura, literatura, psicanálise, semiótica. São Paulo: Imago, 1994.

FONSECA, Raphael. Mestre em História da Arte pela UERJ em seu artigo apresentado a

UNICAMP: Retrato e autorretrato em Nikki S. Lee.

GOMBRICH, E. H. A História da Arte. 16 ed. Rio de Janeiro: LTC, 1999.

HALL, Stuart. A identidade cultural na pós-modernidade. 10 ed. Rio de Janeiro: DP\&A Editora,2005. In: ABREU, Simone Rocha. Autorretrato: inventando a si mesmo. Artigo apresentado a USP.

HAAL, Stuart. Identidade e diferença: uma introdução teórica e conceitual. In: Identidade e diferença: a perspectiva dos estudos culturais. SILVA, Tomaz T. (org.), HALL, Stuart, WOODWARD, Kathryn. -Petrópolis, RJ: Vozes, 2000.

HUYGUE, René. A arte e a alma. Paris: Livraria Bertrand, 1960. In CARVALHO, Saul Ferdinando de Oliveira. Retratos: entre as cores e a materialidade. Dissertação de mestrado. Campinas, 2010.

SCHUH. Cátia Inês. A prospecção pós-moderna da comunicação visual no imaginário de Frida Kahlo. Tese apresentada para obter o grau de doutor, pelo Programa de PósGraduação em Comunicação Social da PUC do Rio Grande do Sul.

REY, Sandra. Da prática à teoria: três instâncias metodológicas sobre a pesquisa em artes visuais. Porto Arte, Porto Alegre: Programa de Pós-Graduação em Artes VisuaisUFRGS, 2002.

SANT'ANNA, Renata. Saber e ensinar arte contemporânea. São Paulo: Panda books, 2010.

SILVA, Nelson do Valle. Uma nota sobre 'raça social' no Brasil. Caderno Cândido Mendes. Estudos Afro-asiáticos, 26, 1995. 


\section{EDUCAÇÃO, ARTES E INCLUSÃO}

VOLUME 11, NÚMERO 1, Ano 2015

ISSN 1984-3178

TÜMPEL, Christian. Rembrandt - images and metaphors. London: Haus Publishing, 2006. In: CARVALHO, Saul Ferdinando de Oliveira. Retratos: entre as cores e a materialidade. Dissertação apresentada ao Instituto de Arte. Campinas: 2010

VANÇAN, Gilberto. Auto-retrato : Eu não eu. 2003. Tese de Mestrado em Artes (Instituto de Artes da UNICAMP) - Instituto de Artes - UNICAMP, Campinas - SP.

WEST, Luise. Retratos familiares: InMemorian. São Paulo, 1998. In CARVALHO, Saul Ferdinando de Oliveira. Retratos: entre as Cores e a materialidade. Dissertação apresentada ao Instituto de Artes da Universidade Estadual de Campinas. 2010.

ZAMBONI, Silvio. A pesquisa em arte: um paralelo entre arte e ciência. Campinas, SP: Autores Associados, 1998. 